\title{
Headache Related to PPE Use during the COVID-19 Pandemic
}

\author{
Jonathan J. Y. Ong ${ }^{1}$ (D) - Amanda C. Y. Chan ${ }^{1}$ (D) Chandra Bharatendu ${ }^{1,2}$ (D) $\cdot$ Hock Luen Teoh $^{1}$ (D) \\ Yee Cheun Chan ${ }^{1}$ (D) Vijay K. Sharma ${ }^{1}$ (1)
}

Accepted: 22 May 2021 / Published online: 15 June 2021

(C) The Author(s), under exclusive licence to Springer Science+Business Media, LLC, part of Springer Nature 2021

\begin{abstract}
Purpose of Review Personal protection equipment (PPE)-associated headache is an unusual secondary headache disorder that predominantly occurs in healthcare workers as a consequence of the donning of protective respirators, face masks and/or eyewear. The appreciation of this entity is important given the significant ramifications upon the occupational health of healthcare workers and could additionally have an impact on persons living with pre-existing headache disorder(s).

Recent Findings There has been a renewed interest and recognition of PPE-associated headaches amongst healthcare professionals, largely brought about by the ongoing COVID-19 pandemic which has besieged healthcare systems worldwide. De novo PPE-associated headaches may present with migrainous or tension-type features and can be viewed as a subtype of external compression headache. The prognosis of the disorder is generally favourable, given that most headaches are short-lived without long-term sequalae. Several aetiologies have been postulated to account for the development of these headaches. Notably, these headaches can affect the occupational health and work performance of healthcare workers.

Summary In this review, we discuss the epidemiology, clinical characteristics, probable etiopathogenesis, management and prognosis of PPE-associated headaches in the context of the COVID-19 pandemic. Future directions for research and PPE development are proposed.
\end{abstract}

Keywords Headache · Personal protection equipment · PPE · Face mask · N95 · Eyewear · Goggles · Coronavirus disease 2019 . Powered air-purifying respirator (PAPR)

\section{Introduction}

Coronavirus disease 2019 (COVID-19) attributed to the severe acute respiratory syndrome coronavirus 2 (SARS-CoV2) was declared a global pandemic by the World Health Organisation (WHO) in March 2021 [1-4]. The pandemic

This article is part of the Topical Collection on Uncommon and/or Unusual Headaches and Syndromes

Jonathan J. Y. Ong

jonathan_ong@nuhs.edu.sg

1 Division of Neurology, National University Hospital and Yong Loo Lin School of Medicine, National University of Singapore, NUHS Tower Block, Level 10, 1E Kent Ridge Road, Singapore 119228, Singapore

2 Stead Family Department of Pediatrics, Division of Medical Genetics and Genomics, University of Iowa Carver College of Medicine, Iowa City, IA, USA continues to be an ongoing public health issue with more than 133 million cases recorded globally [5]. As the main mode of dissemination of the SARS-CoV-2 virus is via respiratory droplets, healthcare personnel worldwide were mandated to wear personal protective equipment (PPE), while caring for suspected or confirmed COVID-19 patients in the course of their duties. Essentially the donning of full PPE necessitates the use of a pre-fitted size-appropriate respirator (e.g. N95 face mask), protective eyewear (goggles or face shield), gown and gloves $[6,7]$.

The most commonly used respirator is the N95 face mask, which has been designed to filter off at least $95 \%$ of particles that are $>0.3 \mathrm{um}$, preventing these particles from entering the lungs. Although coronaviruses measure $0.06-0.14 \mu \mathrm{m}$ in diameter, their small size renders them random Brownian motion, making them more prone for being trapped by the filter. Therefore, N95 respirator masks filter the coronavirus effectively, provided the mask has a proper seal. Therefore, a fit test is necessary before donning these masks [7]. In addition to 
PPE, healthcare professionals working in high-risk hospital areas may also need to use powered air-purifying respirators (PAPR) when aerosol-generating medical procedures (e.g. endotracheal intubation) are performed $[8,9]$. It is worthwhile to note that each country has their own certification standard for each mask type, e.g. the USA (National Institute for Occupational Safety and Health (NIOSH), 42CFR Part 84), Europe (149:2001) and China (KN95, GB2626). The European Union classifies respirator masks into FFP1, FFP2 and FFP3 where FFP stands for filtering face piece. N95 is roughly equivalent to FFP2 and N99 is roughly equivalent to FFP3 masks. FFP1, FFP2 and FFP3 are also called P1, P2 and $\mathrm{P} 3$. In the real-world practice, the donning of PPE is often physically distressing, especially when used for an extended duration as necessitated by outbreaks of infectious diseases with a protracted course, as in the case of COVID-19 [10-12].

Headache arising from the sustained compression of pericranial soft tissues by the wearing of objects with tight bands or straps (e.g. helmets, diving goggles, frontal lux devices) has been previously reported in the literature [13-19]. The pain or discomfort (headache, facial pain, and/or ear lobe discomfort) arising from tight-fitting respirators and their accompanying elastic head straps confers limited tolerability, especially when used for a prolonged period of time [20-22]. Other nonmechanical related adverse effects such as difficulty breathing, dizziness and shortness of breath have also been previously reported as potential etiological factors, affecting the overall satisfaction and occupational health of healthcare professionals [23].

The unprecedented scale of the COVID-19 pandemic provides a hitherto opportunity for the study of PPE-associated headaches amongst healthcare workers, adding to the limited medical literature on this unusual entity. This review shall discuss the epidemiology, clinical features, probable etiopathogenesis, prognosis and management of PPEassociated headaches in the context of the ongoing COVID19 pandemic. Future directions for research and PPE development will also be proposed.

\section{Epidemiology}

The incidence of PPE-associated headaches amongst healthcare workers in the context of the COVID-19 pandemic ranges from $26.5 \%-90.7 \%$ [24, 25••, 26-32, 33•, 34•, 35•, $36{ }^{\bullet}$. In comparison, a study amongst healthcare providers using the N95 face mask during the 2003 severe acute respiratory distress syndrome (SARS) epidemic in Singapore observed that new-onset face mask-associated headaches occurred with an incidence of $37.3 \%$ [37].

Since the start of COVID-19 in December 2019, there have been a total of 6 published studies specifically conducted to understand PPE-associated headache amongst healthcare

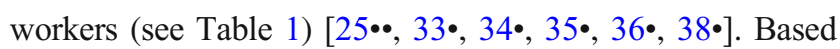
on these studies, several factors have been found to confer a greater likelihood of developing de novo PPE-associated headaches. These include having a pre-existing primary headache diagnosis (e.g. migraine or tension-type headache) [25••, 34•], engaging in shift-work lasting more than $8 \mathrm{~h} \mathrm{[38 \bullet}$ or up to $12 \mathrm{~h}\left[23,38^{\bullet}\right]$ at a stretch, and the use of a filter mask (as opposed to a surgical mask) [35•]. The combined usage of PPE (N95 respirator and protective eyewear) for $>4 \mathrm{~h}$ per day [25••] or the use being a healthcare worker (in particular being a nurse) or having a history of asthma was also found to correlate with the development of such headaches. Interestingly, Caglar et al. reported that every hour spent using PPE increased the risk of developing new symptoms (including headache) by 1.38 times [31].

\section{Clinical Features of De Novo PPE-Associated Headaches}

Recently published studies specifically looking at PPEassociated headache amongst healthcare workers during COVID-19 provide interesting insights into the phenotype of this unusual entity which until now has been infrequently reported [25••, 33•, 34•, 35•, 36•, 38•] (see Table 1).

The HAPPE (headaches associated with personal protective equipment) study was the first study worldwide to characterise the clinical features of de novo PPE-associated headaches in the context of COVID-19 [25••]. This and subsequent studies conducted have helped to define the following clinical features:

(a) Headache lateralisation. Headache is usually bilateral with the experienced discomfort localising to areas where the protective respirator and eyewear, and their accompanying straps, makes contact upon the head, face and neck (see Fig. 1) [25••, 36•, 38•].

(b) Headache quality. Usually a 'pressure', 'heaviness' or 'pulling' sensation, although some may experience a 'throbbing' headache [25••, 33•, 36•].

(c) Headache intensity. Usually mild to moderate in intensity although a more severe headache may be experienced in a proportion of individuals [25••, 33•, 34•, 36•].

(d) Headache duration. Attacks have been reported to range from $<30 \mathrm{~min}$ to $2 \mathrm{~h}[25 \bullet \bullet, 34 \bullet, 36 \bullet, 38 \bullet]$.

(e) Associated symptoms. A proportion may experience nausea and/or vomiting, photophobia, phonophobia, neck discomfort and movement sensitivity [25••, 33•]. Fatigue, tachypnoea, dizziness and palpitations have also been observed [36॰].

(f) ICHD-3 (2018) Criteria for 4.6 .1 external compression headache $(E C H)$ [39]. In two studies, the criteria for $\mathrm{ECH}$ 


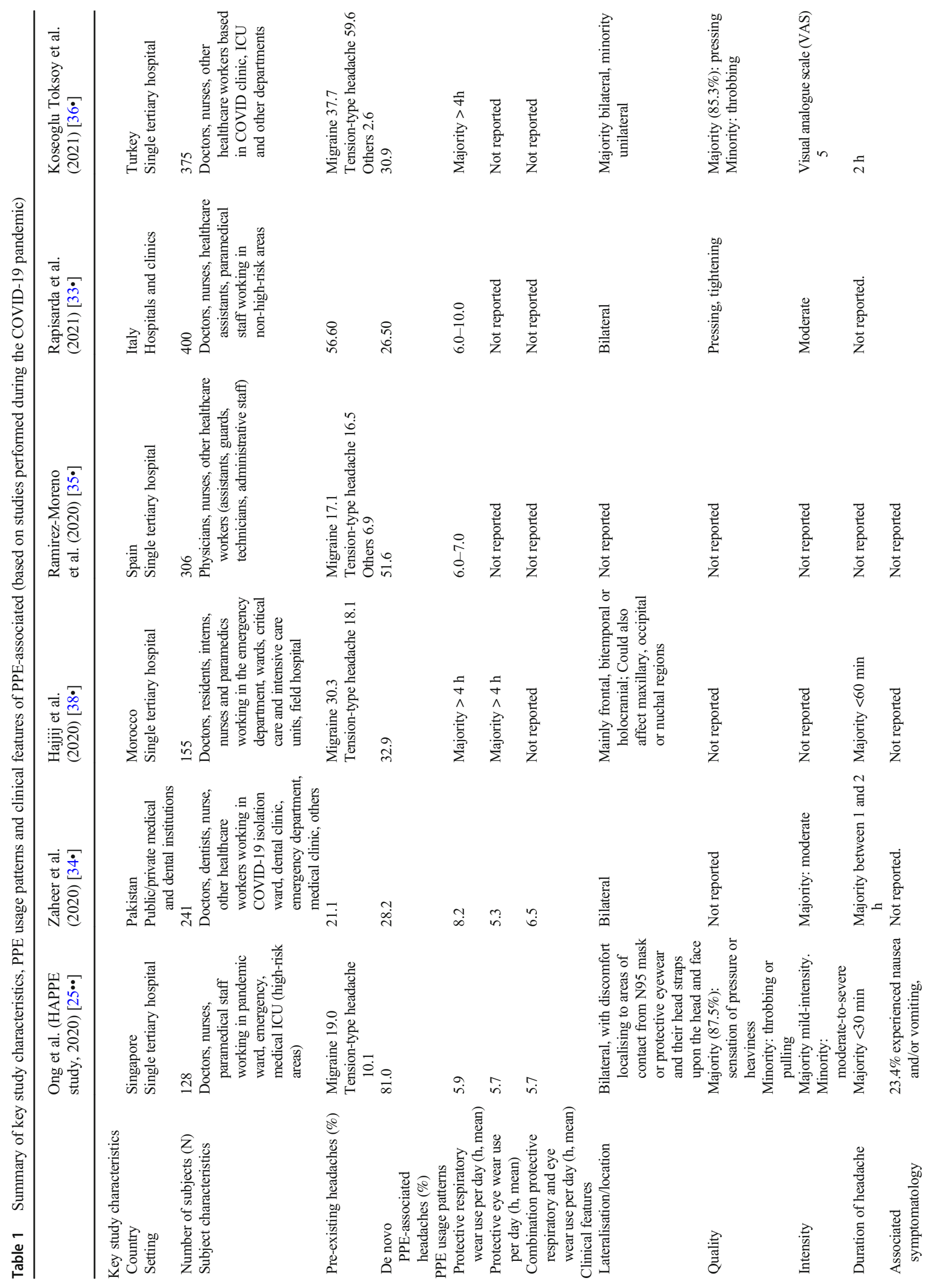




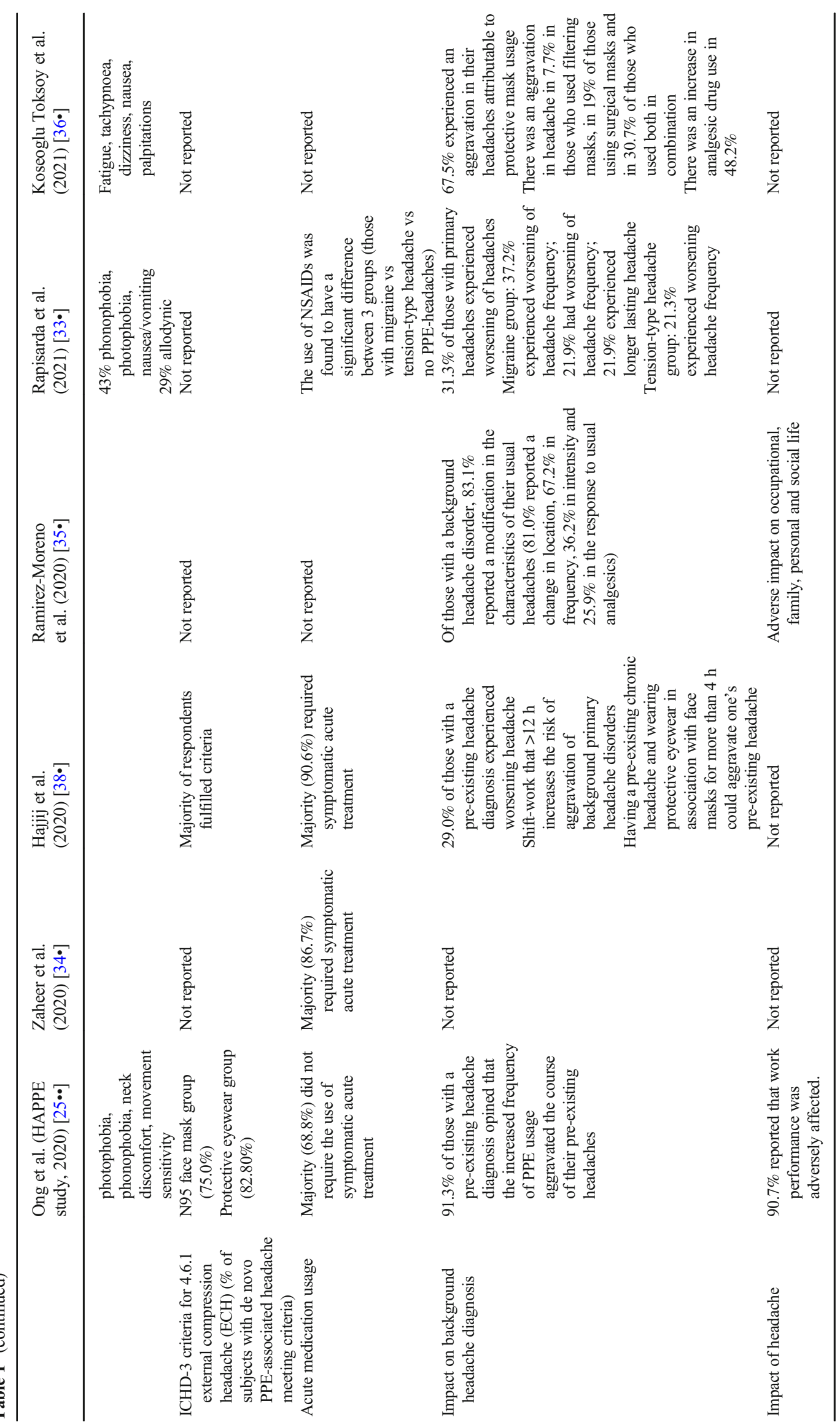


(see Table 2) were fulfilled by the majority who developed de novo PPE-associated headaches [25••, 38•].

In summary, de novo PPE-associated headache can present with migrainous or tension-type features and can be viewed as a subtype of external compression headache.

\section{Pre-existing Headache Diagnosis and Concomitant PPE-Associated Headaches}

Multiple reports have revealed that de novo PPE-associated headaches can affect the course of migraine or tension-type headache amongst healthcare workers with pre-existing pri-

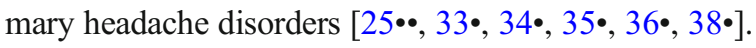

The incidence of de novo PPE-associated headaches amongst those with a background headache disorder (e.g. migraine, tension-type headache) has been reported to range from 29.0 to $93.5 \%$ [25••, 34•, 38•].

The increased frequency of PPE usage has been found to correlate with an increase in attack frequency and duration as well as the administration frequency and response of acute medication for those with pre-existing headaches, although other contributing factors such as sleep deprivation, physical stress, psychological stress, irregular mealtimes and inade-

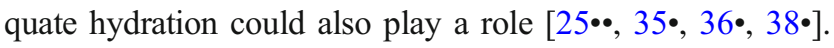
Similar to those with purely de novo PPE-associated headaches, work performance can be adversely affected [25••, $33 \bullet$.

Additionally, having a pre-existing headache diagnosis as well as the donning of protective eyewear in combination with face mask for more than $4 \mathrm{~h}$ correlated with the development of de novo PPE-associated headaches in this population [25••, $36 \bullet$.

\section{Etiopathogenesis}

Several proposed aetiologies and mechanisms have been postulated to explain the development of PPE-associated headaches. Mechanical and physical factors such as pressure, tension or tractional forces from the respirator and/or protective eyewear and their accompanying bands or straps can cause localised tissue damage or exert an irritative effect on the superficial sensory nerves (in particular trigeminal or occipital nerve branches) innervating the face, head and cervical regions [15] (see Figs. 2 and 3). Additionally, neck strain from the donning of such equipment could trigger cervicogenic or tension-type headache $[40,41]$. The resultant peripheral sensitisation activates the trigeminocervical complex through nociceptive information transmitted via different branches of the trigeminal nerve through the trigeminal ganglia and brainstem to the higher cortical areas, thereby triggering such headaches [42]. Additionally, a compressive neuralgia affecting superficial sensory nerves [43] or skin breakdown [44, 45] could also serve as contributory factors for headache development.

At present, there is conflicting opinions pertaining to the causative role of hypoxemia and/or hypercapnia towards the development of PPE-associated headaches. Theoretically, the donning of the N95 respirator could alter the physiology of respiration leading to increased breathing resistance which in turn could increase respiratory muscle usage, potentially affecting carbon dioxide $\left(\mathrm{CO}_{2}\right)$ [46] and oxygen levels [47, 48]. Previous reports have suggested that such alterations can cause altered cerebral haemodynamics due to hypoxemia and $\mathrm{CO}_{2}$ retention, leading to headache even after a few minutes of wearing the N95 respiratory [23, 49]. However, such physiological changes were reported to neither cause a significant change in the blood concentrations of these gases [39] nor did they translate into clinically relevant effects in healthy individuals [47, 48, 50, 51]. On the contrary, it was found that speech and low physical activity rates while wearing protec-
Fig. 1 Frontal and side profiles of a healthcare worker donning the N95 respirator and protective eyewear (either goggles or face shield) in combination (a-f). Posterior profile demonstrating where the edges of the N95 face mask and goggles and their accompanying straps contact the head, neck and face (g). Adapted with permission from $[25 \bullet \bullet]$

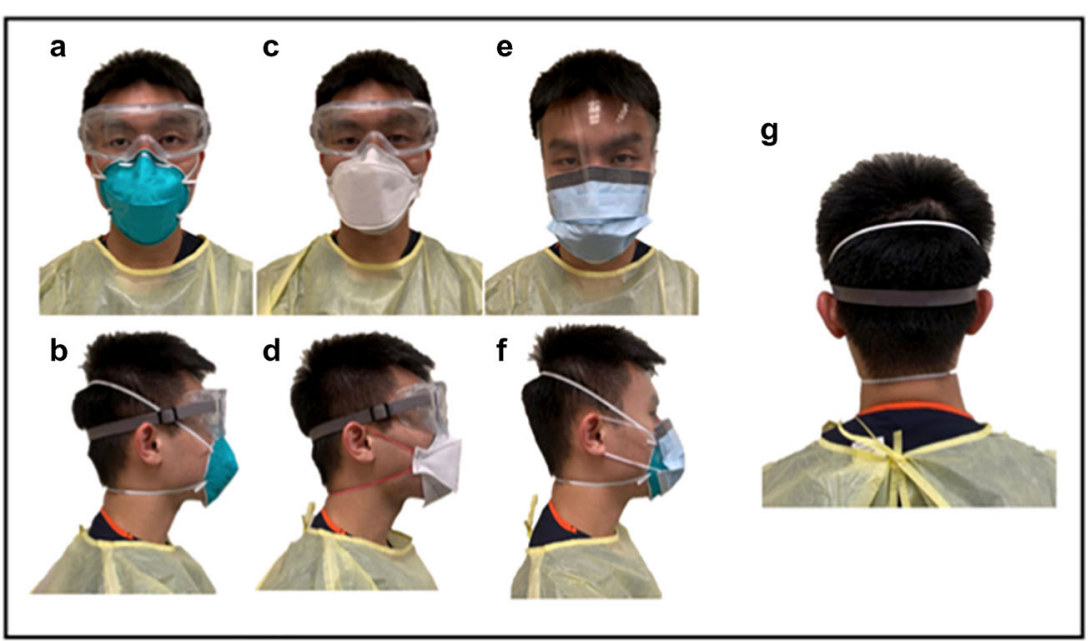


Table 2 International Classification of Headache Disorders, 3rd Edition (ICHD-3) (2018) criteria for external compression headache [13]

1. At least 2 episodes of headache fulfilling criteria $2-4$

2. Brought on by and occurring within $1 \mathrm{~h}$ during sustained external compression of the forehead or scalp

3. Maximal at the site of external compression

4. Resolving within $1 \mathrm{~h}$ after external compression is relieved

5. Not better accounted for by another ICHD-3 diagnosis

tive respiratory devices could lead to $\mathrm{CO}_{2}$ rebreathing, causing discomfort and reduced tolerability [52]. Apart from the perturbations in respiratory homeostasis, the use of PPE has been found to cause considerable changes in other physiological parameters (e.g. heart rate, perfusion index), indirectly causing a constellation of adverse effects including headaches, tiredness, difficulty breathing and palpitations especially after prolonged shift working [32].

In an attempt to provide further clarification of the effect of hypercapnia and PPE-associated headaches, our group evaluated the cerebral haemodynamic changes of 154 healthcare workers during the COVID-19 pandemic, who donned either the N95 respirator alone or in combination with PAPR [8••]. Cerebral haemodynamic changes were assessed via transcranial Doppler (TCD) monitoring of the middle cerebral artery (see Fig. 4). In this study, the mean flow velocity (MFV) and pulsatility index (PI) were recorded at baseline, $5 \mathrm{~min}$ after

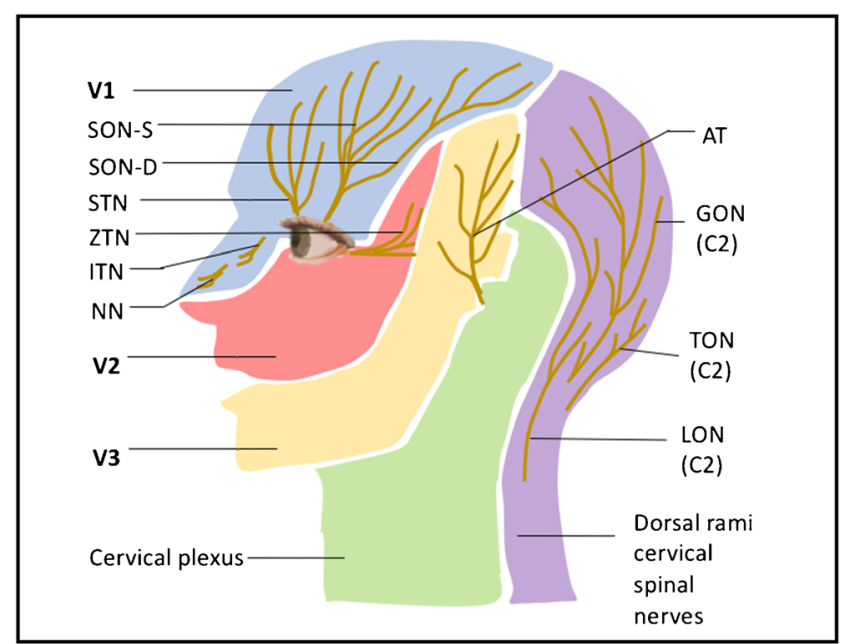

Fig. 3 Sensory innervation of the head. Auriculotemporal nerve (AT); deep branch of the supraorbital nerve (SON-D); greater occipital nerve (GON); infratrochlear nerve (ITN); lesser occipital nerve (LON); mandibular branch of the trigeminal nerve (V3); maxillary branch of the trigeminal nerve (V2); nasal nerve $(\mathrm{NN})$; ophthalmic branch of the trigeminal nerve (V1); superficial branch of the supraorbital nerve (SON-S); supratrochlear nerve (STN); third occipital nerve (TON); zygomaticotemporal nerve (ZTN). The reader will appreciate the clinico-anatomical relevance when this diagram is compared with Fig. 2. Adapted with permission from $[25 \cdot \bullet]$

donning the N95 respirator and 5 min after donning PAPR. These TCD parameters have been previously validated a priori to be reliable surrogates of cerebral blood flow and
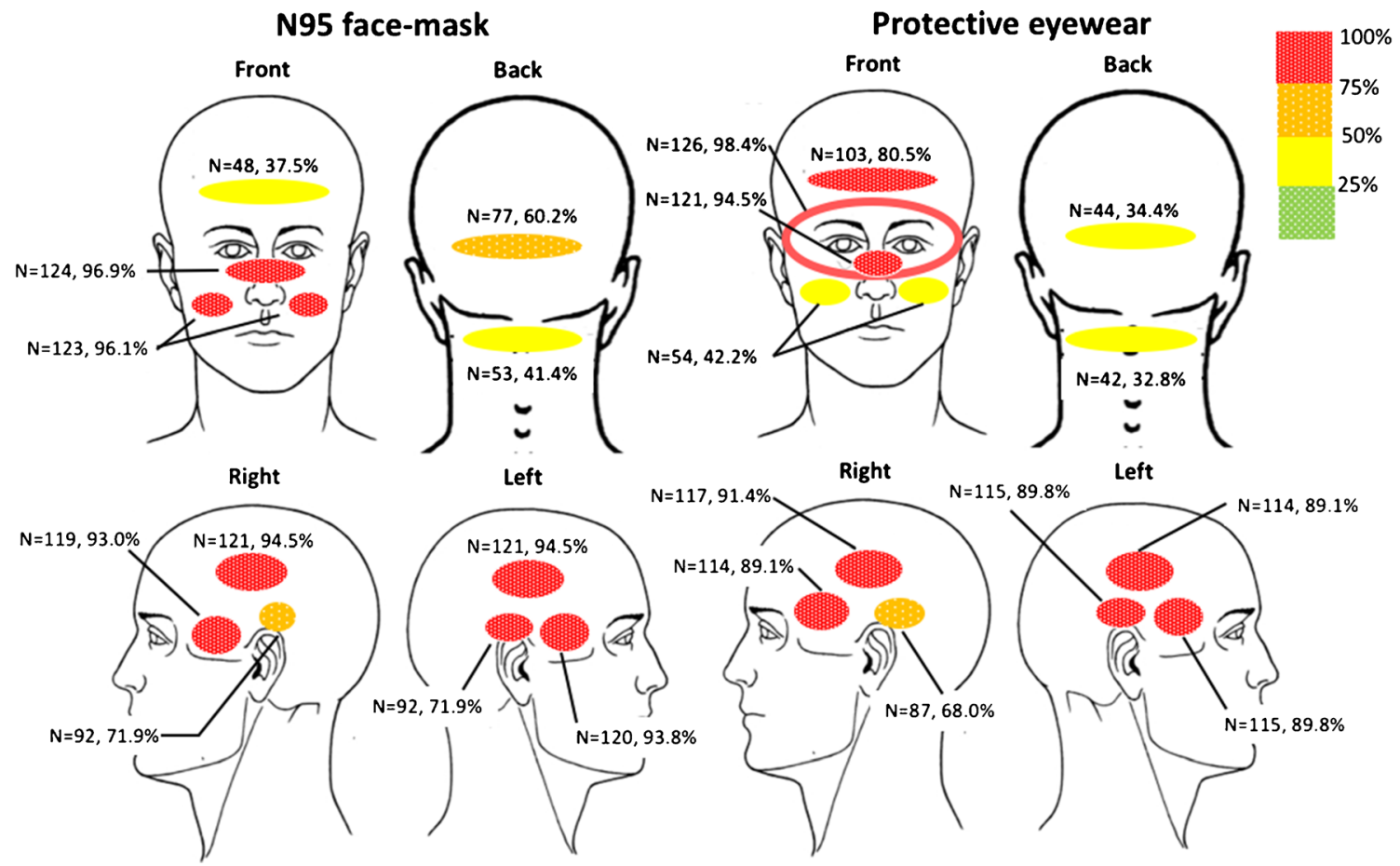

Left

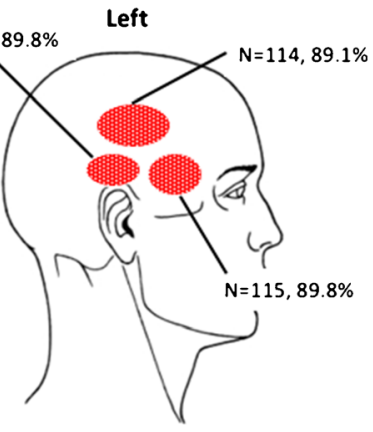

Fig. 2 Anatomical localisation and frequency distribution amongst 128 respondents from the HAPPE study who reported de novo PPE-related headaches. The shaded areas indicate the regions where discomfort was

experienced and generally corresponds to the areas of physical contact from the N95 respirator or protective eyewear and their accompanying straps. Adapted with permission from [25••] 
vascular tone. These parameters can be altered by changes in the partial pressure of $\mathrm{CO}_{2}$ in arterial blood [53]. The end-tidal carbon dioxide $\left(\mathrm{ETCO}_{2}\right)$ pressure was also assessed via a cannula. The donning of N95 respirator resulted in a significant increase in MFV and a decrease in PI while $\mathrm{ETCO}_{2}$ increased. In a subset of participants donning the N95 respirator in combination with PAPR, we demonstrated the normalisation of PI, accompanied by normalisation of $\mathrm{ETCO}_{2}$ after $5 \mathrm{~min}$. It is possible that the N95 respirator could cause an expansion of the effective dead space volume around the mouth and nose, resulting in hypercapnia [54], which could be reversed by the concurrent use of PAPR leading to the normalisation of $\mathrm{ETCO}_{2}$ as well as cerebral haemodynamic parameters. We postulate that the positive pressure generated by PAPR could have led to a relative hypocapnia by increasing the concentration of oxygen inside the hood and through positive pressure-assisted exhalation. Our findings suggest a possible contributory role of hypercapnic cerebral vasodilatation as one possible mechanism giving rise to PPE-associated headaches, which could be mitigated by the combined use of PAPR. In addition, our subjects opined that the combined use of the N95 respirator and PAPR was more tolerable as compared to when the N95 respirator was used in isolation.

In a separate study, our group further evaluated the concentration of $\mathrm{ETCO}_{2}$ amongst 11 healthy individuals when various PPE equipment were used [55]. Carbon dioxide levels were measured under 4 different conditions-(a) during regular breathing with no mask worn (b) with donning of the JustAir® PAPR (c) or KN95 respirator (Emercate, Shenzhen, China) (d) or a valved respirator (model 7502/37082(AAD) (3M, St. Paul, $\mathrm{MN})$ ). Serial $\mathrm{ETCO}_{2}$ measurements were done using a nasal cannula for $15 \mathrm{~min}$ for each PPE configuration to evaluate whether NIOSH limits were breached. We found that the use of face masks (KN95 and valved respirator) resulted in significant increases in $\mathrm{ETCO}_{2}$ concentrations, which exceeded the 8-h NIOSH exposure threshold limit value-time-weighted average (TLV-TWA). However, these concentration increases did not breach short-term (15-min) limits. Notably these levels were considerably lower than the long-term (8-h) NIOSH limits during the donning of JustAir ${ }^{\circledR}$ PAPR. Our findings lend further support towards the use of PAPR, alone or in combination with face masks, which may be especially pertinent in circumstances where an extended period of PPE donning is anticipated.

\section{Prognosis, Management and Implications on Occupational Health and Quality of Life}

Our experience from the HAPPE study and other reports suggest that PPE-associated headaches generally have a favourable prognosis as attacks are mostly short-lived with no prolonged sequelae $[25 \bullet \bullet, 33 \bullet, 34 \bullet, 35 \bullet, 36 \bullet, 38 \bullet$. While the majority of the subjects in the HAPPE study [25••] did not
Fig. 4 An example of serial transcranial Doppler (TCD) changes measured from a healthy subject during the donning of $\mathrm{N} 95$ respirator mask alone and in combination with PAPR. While breathing ambient room air, the Doppler spectra from the right middle cerebral artery showed a MFV of $46.6 \mathrm{~cm} / \mathrm{s}$ and PI 0.96 (A). Post-donning N95 respirator mask for $5 \mathrm{~min}, \mathrm{MFV}$ increased to $53.9 \mathrm{~cm} / \mathrm{s}$ while PI decreased to 0.68 (B). However, both MFV and PI returned to near-baseline 5 min after donning of PAPR and N95 respirator in combination (C). Adapted with permission from $[8 \cdot \bullet]$

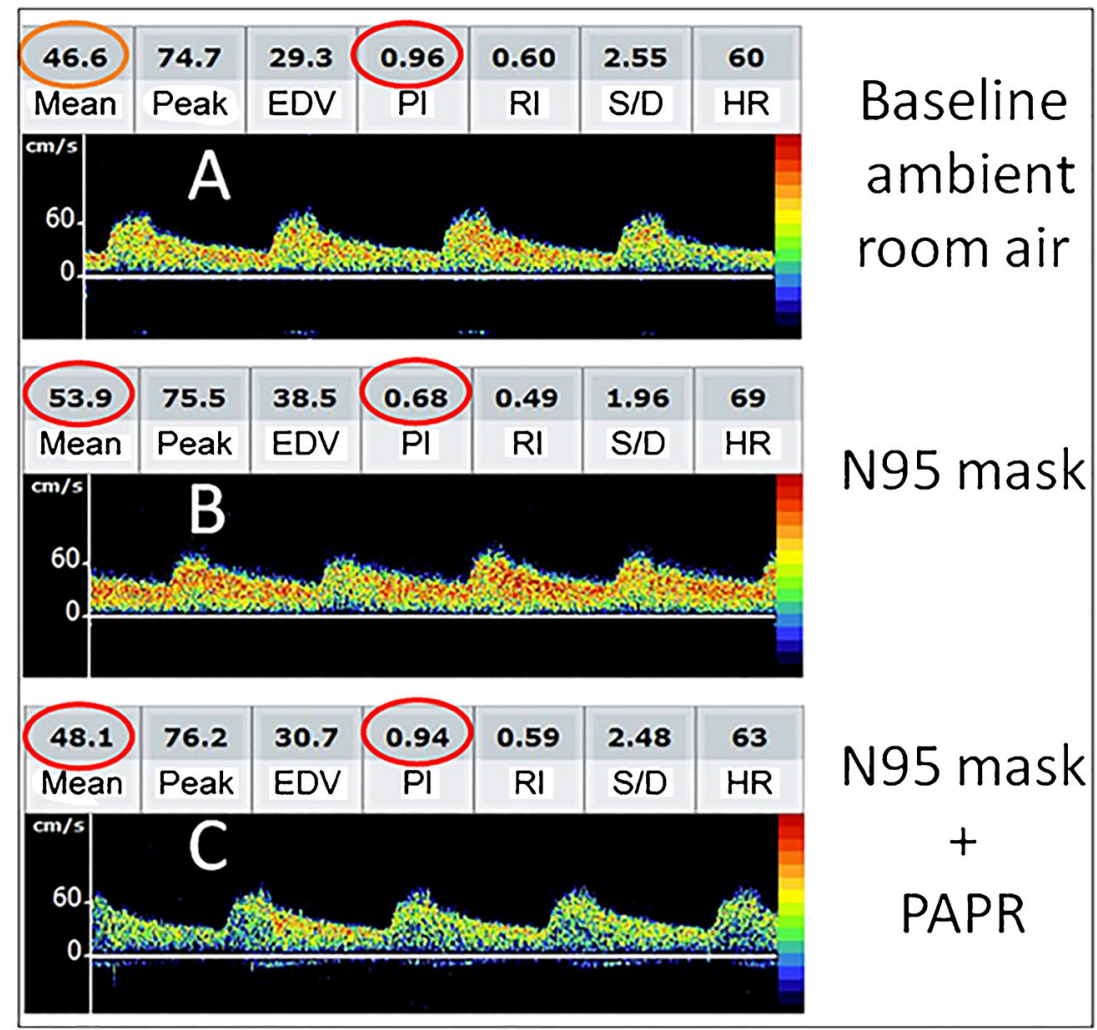


require symptomatic acute treatment, Zaheer et al. [34•] and Hajjij et al. [38•] observed that the majority of their subjects required the administration of acute treatment, with most using simple analgesics such as paracetamol and nonsteroidal anti-inflammatory drugs (NSAIDS). Triptans and opioids were rarely needed. This difference perhaps reflects the variance in demographics and working conditions that exists amongst different study populations. PPE-associated headaches have also been perceived to negatively impact upon the occupational health, work performance and productivity of healthcare workers with or with a pre-existing headache diagnosis $[25 \cdot \bullet]$. These headaches also had an impact on family, personal or social life, especially in those with a background headache disorder, with a greater effect on those who used a respirator as opposed to a surgical mask [35०]. For those who have a pre-existing primary headache disorder (e.g. migraine or tension-type headache), multiple studies have revealed that PPE-associated headaches could adversely aggravate the course of their background headaches in terms of frequency, intensity and acute medication usage $[25 \bullet, 33 \bullet$, $34 \cdot, 35 \bullet, 36 \bullet, 38 \bullet]$.

In general, unless there are other atypical features, investigations are not routinely required given the clear temporal relationship of PPE usage and headache development. Interestingly, a study by Martin-Rodriguez et al. reported that an elevated baseline blood creatinine level as compared to that measured after a 4-h shift could potentially be a useful blood biomarker that could predict the development of PPE-associated headaches [56]. Clearly more studies are necessary to elucidate the clinical relevance and utility of this initial finding.

At present, there are no robust evidence-based treatment strategies for the management of PPE-associated headaches. Given that the COVID-19 pandemic is far from over, one may postulate that headache frequency, intensity, use of analgesics and work performance may continue to worsen if the pandemic is sustained for a longer duration. Shorter duty hours and the institution of frequent rest breaks translate into a shorter duration of PPE usage and might be a viable long-term strategy to avoid the adverse impact of PPE usage, especially when used for an extended duration [25*0. The use of PAPR alone (those with double filters) or together with a separate respirator (e.g. N95 mask) for healthcare workers on longer shifts could also be advocated, especially for susceptible healthcare workers $[8 \cdot \bullet, 55]$. Environmental modification strategies such as the maintenance of an optimal ambient temperature and adequate ventilation may additionally help to alleviate the discomfort of PPE usage especially in climates where high temperatures and humidity are experienced throughout the year [28]. The avoidance of known headache trigger factors such as sleep deprivation, physical and psychological stress, irregular mealtimes and inadequate hydration should be incorporated in the management strategy to decrease the propensity of headache occurrence $[42,57-60]$. Simple measures to decrease PPE- related pressure effects such as wearing of mask straps across the crown to prevent pressure on the ears or application of alcohol-free film barriers or petroleum jelly on could potentially help as well $[44,45,61]$.

\section{Future Directions}

Given that the use of PPE will likely become more widespread in the foreseeable future, PPE design in addition to the promotion of strategies to guarantee the safety of healthcare workers while catering to their work productivity and overall quality of life will be key in the battle against COVID-19 and other emerging infectious diseases in the coming years.

Although the vast majority of PPE-associated headaches fulfilled the criteria for ECH (see Table 1), a proportion of healthcare workers had time intervals exceeding the stipulated 60-min time limit in terms of the onset from PPE donning and resolution of headache post-PPE doffing [25••]. The extended duration of PPE usage amongst healthcare workers during COVID-19 is largely brought about by necessity as mandated by infectious diseases protocols and represents a clear departure from prior usage patterns pre-pandemic. It is plausible that despite any discomfort arising from PPE usage, frontline healthcare workers may have to endure the discomfort without the opportunity for frequent adjustments or removal. As astutely reported by Farronato et al., the dental professionals in their cohort had usually took off their masks in between patients, which is why the time spent using PPE was not found to be correlated associated with headaches in their study [30]. Notably, a proportion of PPE-associated headaches have been found to be associated with migrainous symptomatology $[25 \bullet \bullet, 33 \bullet]$. It is possible that in predisposed subjects, if the stimulus is prolonged, external compression may result in a more severe migraine attack [62]. From an anatomic standpoint, the head and neck regions where pain is localised may also be consistent with migraine or tension-type headache (see Fig. 2). Further larger-scale systematic field studies are necessary to validate and determine the phenotypic variance of these headaches amongst frontline healthcare workers. Perhaps in the next iteration of the ICHD, the diagnostic criteria of ECH could be better defined through the inclusion of 'migrainous' and 'tension-type' subtypes to better characterise the phenotype of ECH.

At present, conventional PPE prioritise the adequacy of fit over comfort or tolerability, especially when these equipment are donned for a prolonged duration as in the context of disease outbreaks $[11,63]$. Mask and protective eyewear designs rely heavily on elastic straps. Furthermore, prolonged PPE usage can cause thermal discomfort, as a consequence of moist warm air accumulating within the confines of the mask and protective eye-wear micro-environment, further contributing to the development of de novo PPE-associated 
headache, especially in hot and humid environments [64, 65], where heat stress, dehydration and associated cognitive impairment could additionally aggravate the effects of extended PPE use [66, 67]. These factors have an important bearing on PPE compliance amongst healthcare workers, with consequent ramifications on occupational health, workplace safety, productivity and ultimately job satisfaction. Clearly, there is an urgent need to develop the nextgeneration PPE, perhaps through the use of novel material engineering solutions, which will not only be safe but also better tolerated, and consequently less propensity for the development of headaches $[68,69 \cdot \bullet]$. Such endeavours are important as they help increase the compliance and proper usage of PPE and thus improve occupational safety amongst healthcare workers $[11,27,67,68]$.

\section{Conclusions}

The use of PPE amongst frontline healthcare workers to protect themselves against SARS-CoV-2 is undeniably essential. PPE-associated headaches are increasingly recognised as a form of secondary headache that has recently surfaced with renewed interest owing to the ongoing COVID-19 pandemic. This disorder has important occupational health ramifications given that the trajectory of the pandemic is likely to be protracted. The reality of a contracted healthcare workforce translating into the need for extended working hours or shifts potentially increases the exposure to viral load. There is thus an urgent need to improve the design of existing PPE options, which not only fulfils conventional safety standards but also user comfort and tolerability. This is perhaps one of the biggest issues facing healthcare professionals today, which needs global prioritisation for not only COVID-19 but also for future pandemics of similar proportions.

Availability of Data and Materials Not applicable.

Code Availability Not applicable.

Author Contribution All the authors contributed in the conceptualisation, initial draft, critical revision and final approval of the manuscript.

\section{Declarations}

Ethics Approval Not applicable.

Consent to Participate Not applicable.

Consent for Publication Not applicable.

Conflict of Interest None of the authors declare any competing interests associated with this manuscript.
Human and Animal Rights and Informed Consent Not applicable.

\section{References}

Papers of particular interest, published recently, have been highlighted as:

- Of importance

•. Of major importance

1. Wu Z, McGoogan JM. Characteristics of and important lessons from the coronavirus disease 2019 (COVID-19) outbreak in China: summary of a report of 72314 cases from the Chinese Center for Disease Control and Prevention. JAMA. 2020;323(13):1239-42. https://doi.org/10.1001/jama.2020.2648.

2. Huang C, Wang Y, Li X, Ren L, Zhao J, Hu Y, et al. Clinical features of patients infected with 2019 novel coronavirus in Wuhan, China. Lancet. 2020;395(10223):497-506. https://doi. org/10.1016/S0140-6736(20)30183-5.

3. Zhu N, Zhang D, Wang W, Li X, Yang B, Song J, et al. A novel coronavirus from patients with pneumonia in China, 2019. N Engl J Med. 2020;382(8):727-33. https://doi.org/10.1056/ NEJMoa2001017.

4. WHO. Listings of WHO's response to COVID-19. 2020; Available from: https://www.who.int/news/item/29-06-2020-covidtimeline. Accessed on April 08, 2021.

5. CCfSSa, E. Coronavirus COVID-19 global cases. 2021; Available from: https://gisanddata.maps.arcgis.com/apps/opsdashboard/ index.html\#/bda7594740fd40299423467b48e9ecf6. Accessed on April 08, 2021.

6. Rebmann T, Alexander S, Bartley J, Cain T, Citarella B, Cloughessy, $\mathrm{M}$, et al. APIC position paper: extending the use and/or reusing respiratory protection in healthcare settings during disasters. 2009. Available from: https://www.apic.org/Resource_ TinyMceFileManager/Advocacy-PDFs/APIC Position_Ext the Use_and_or_Reus_Resp_Prot_in_Hlthcare_Settings 12091.pdf. Accessed June 62021.

7. Goh Y, Tan BYQ, Bhartendu C, Ong JJY, Sharma VK. The face mask: how a real protection becomes a psychological symbol during Covid-19? Brain Behav Immun. 2020;88:1-5. https://doi.org/ 10.1016/j.bbi.2020.05.060.

8.• Bharatendu C, et al. Powered Air purifying respirator (PAPR) restores the N95 face mask induced cerebral hemodynamic alterations among healthcare workers during COVID-19 outbreak. J Neurol Sci. 2020;417:117078. https://doi.org/10.1016/j.jns.2020. 117078. An interesting study that provides clarification on the association of hypercapnia-induced cerebrovascular haemodynamic changes and the development of PPE-associated headaches (using N96 respirator and/or PAPR) through the use of transcranial Doppler ultrasound.

9. Roberts V. To PAPR or not to PAPR? Can J Respir Ther. 2014;50(3):87-90.

10. Wong JEL, Leo YS, Tan CC. COVID-19 in Singapore-current experience: critical global issues that require attention and action. JAMA. 2020;323(13):1243-4. https://doi.org/10.1001/jama.2020.2467.

11. Or PP, Chung JW, Wong TK. A study of environmental factors affecting nurses' comfort and protection in wearing $N 95$ respirators during bedside procedures. J Clin Nurs. 2018;27(7-8):e1477-84. https://doi.org/10.1111/jocn.14268.

12. Powell JB, Kim JH, Roberge RJ. Powered air-purifying respirator use in healthcare: Effects on thermal sensations and comfort. $\mathrm{J}$ Occup Environ Hyg. 2017;14(12):947-54. https://doi.org/10. 1080/15459624.2017.1358817. 
13. Headache Classification Committee of the International Headache Society (IHS) The International Classification of Headache Disorders, 3rd edition. Cephalalgia, 2018. 38(1): p. 1-211. https:// doi.org/10.1177/0333102417738202

14. Rahmani Z, Kochanek A, Astrup JJ, Poulsen JN, Gazerani P. Helmet-induced headache among Danish military personnel. Scand J Public Health. 2017;45(8):818-23. https://doi.org/10. $1177 / 1403494817731417$.

15. Krymchantowski AV. Headaches due to external compression. Curr Pain Headache Rep. 2010;14(4):321-4. https://doi.org/10. 1007/s11916-010-0122-x.

16. Pestronk A, Pestronk S. Goggle migraine. N Engl J Med. $1983 ; 308(4): 226-7$. https://doi.org/10.1056/ nejm198301273080422.

17. Jacobson RI. More "goggle headache": supraorbital neuralgia. N Engl J Med. 1983;308(22):1363. https://doi.org/10.1056/ NEJM198306023082219.

18. O'Brien JC Jr. Swimmer's headache, or supraorbital neuralgia. Proc (Bayl Univ Med Cent). 2004;17(4):418-9. https://doi.org/10. 1080/08998280.2004.11928006.

19. Krymchantowski A, Barbosa JS, Cvaigman M, Lorenzatto W, Silva MT. Helmet-related, external compression headache among police officers in Rio de Janeiro. MedGenMed. 2004;6(2):45.

20. Shenal BV, Radonovich LJ Jr, Cheng J, Hodgson M, Bender BS. Discomfort and exertion associated with prolonged wear of respiratory protection in a health care setting. J Occup Environ Hyg. 2012;9(1):59-64. https://doi.org/10.1080/15459624.2012.635133.

21. Radonovich LJ Jr, et al. Respirator tolerance in health care workers. JAMA. 2009;301(1):36-8. https://doi.org/10.1001/jama. 2008.894

22. Szeinuk J, Beckett WS, Clark N, Hailoo WL. Medical evaluation for respirator use. Am J Ind Med. 2000;37(1):142-57. https://doi. org/10.1002/(sici)1097-0274(200001)37:1<142::aid-ajim11>3.0. co;2-k.

23. Rebmann T, Carrico R, Wang J. Physiologic and other effects and compliance with long-term respirator use among medical intensive care unit nurses. Am J Infect Control. 2013;41(12):1218-23. https://doi.org/10.1016/j.ajic.2013.02.017.

24. Ipek, S., et al., Is N95 face mask linked to dizziness and headache? Int Arch Occup Environ Health, 2021. https://doi.org/10.1007/ s00420-021-01665-3

25.• Ong JJY, et al. Headaches associated with personal protective equipment - a cross-sectional study among frontline healthcare workers during COVID-19. Headache. 2020;60(5):864-77. https://doi.org/10.1111/head.13811. The first study worldwide on PPE-associated headaches performed during COVID-19, detailing the clinical characteristics and phenotype of the disorder. The study found that the majority of PPE-associated headaches fulfil the ICHD-3 criteria for external compression headache $(\mathrm{ECH})$, suggesting that this entity may represent a subtype of ECH.

26. Thiagarajan S, Shetty P, Gulia A, Prakash G, Pramesh CS, Puri A. A survey of personnel protective equipment's (PPE) use and comfort levels among surgeons during routine cancer surgery in the COVID-19 pandemic. Indian J Surg Oncol. 2021:1-9. https://doi. org/10.1007/s13193-021-01316-6.

27. Kumar S, Singh A. Prolonged use of $n 95$ mask a boon or bane to healthcare workers during Covid-19 pandemic. Indian J Otolaryngol Head Neck Surg. 2021:1-4. https://doi.org/10.1007/ s12070-021-02396-0.

28. Swaminathan R, Mukundadura BP, Prasad S. Impact of enhanced personal protective equipment on the physical and mental wellbeing of healthcare workers during COVID-19. Postgrad Med J. 2020:postgradmedj-2020-139150. https://doi.org/10.1136/ postgradmedj-2020-139150.
29. Garra GM, Parmentier D, Garra G. Physiologic effects and symptoms associated with extended-use medical mask and N95 respirators. Ann Work Expo Health. 2021. https://doi.org/10. 1093/annweh/wxab010.

30. Farronato $\mathrm{M}$, et al. A scoping review of respirator literature and a survey among dental professionals. H. 2020;17(16). https://doi.org/ 10.3390/ijerph17165968.

31. Caglar A, et al. Symptoms associated with personal protective equipment among frontline healthcare professionals during the COVID-19 pandemic. Disaster Med Public Health Prep. 2020:115. https://doi.org/10.1017/dmp.2020.455.

32. Choudhury A, Singh M, Khurana DK, Mustafi SM, Ganapathy U, Kumar A, et al. Physiological effects of N95 FFP and PPE in healthcare workers in COVID intensive care unit: a prospective cohort study. Indian J Crit Care Med. 2020;24(12):1169-73. https://doi.org/10.5005/jp-journals-10071-23671.

33. Rapisarda L, et al. Facemask headache: a new nosographic entity among healthcare providers in COVID-19 era. Neurol Sci. 2021;42(4):1267-76. https://doi.org/10.1007/s10072-021-050758. One of a series of 6 studies that was performed to specifically assess PPE-associated headaches since the start of COVID-19, adding to the literature on this uncommon entity.

34. Zaheer R, et al. Association of personal protective equipment with de novo headaches in frontline healthcare workers during COVID19 pandemic: a cross-sectional study. Eur J Dent. 2020;14(S 01): S79-85. https://doi.org/10.1055/s-0040-1721904. One of a series of 6 studies that were performed to specifically assess PPEassociated headaches since the start of COVID-19, adding to the literature on this uncommon entity.

35. Ramirez-Moreno JM, et al. Mask-associated 'de novo' headache in healthcare workers during the COVID-19 pandemic. Occup Environ Med. 2020. https://doi.org/10.1136/oemed-2020-106956. One of a series of 6 studies that were performed to specifically assess PPE-associated headaches since the start of COVID-19, adding to the literature on this uncommon entity.

36. Koseoglu Toksoy $\mathrm{C}$, et al. Headache related to mask use of healthcare workers in COVID-19 pandemic. Korean J Pain. 2021;34(2):241-5. https://doi.org/10.3344/kjp.2021.34.2.241. One of a series of 6 studies that were performed to specifically assess PPE-associated headaches since the start of COVID-19, adding to the literature on this uncommon entity.

37. Lim EC, et al. Headaches and the N95 face-mask amongst healthcare providers. Acta Neurol Scand. 2006;113(3):199-202. https://doi.org/10.1111/j.1600-0404.2005.00560.x.

38. Hajjij A, et al. Personal protective equipment and headaches: cross-sectional study among Moroccan healthcare workers during COVID-19 pandemic. Cureus. 2020;12(12):e12047. https://doi. org/10.7759/cureus.12047. One of a series of 6 studies that were performed to specifically assess PPE-associated headaches since the start of COVID-19, adding to the literature on this uncommon entity.

39. Yalciner G, Babademez MA, Gul F, Serifler S, Bulut KS, Ozturk L. Consequences of FFP3 mask usage on venous blood gases. Ir J Med Sci. 2021. https://doi.org/10.1007/s11845-020-02474-2.

40. Liang Z, Galea O, Thomas L, Jull G, Treleaven J. Cervical musculoskeletal impairments in migraine and tension type headache: a systematic review and meta-analysis. Musculoskelet Sci Pract. 2019;42:67-83. https://doi.org/10.1016/j.msksp.2019.04.007.

41. Barmherzig R, Kingston W. Occipital neuralgia and cervicogenic headache: diagnosis and management. Curr Neurol Neurosci Rep. 2019;19(5):20. https://doi.org/10.1007/s11910-019-0937-8.

42. Goadsby PJ, Holland PR, Martins-Oliveira M, Hoffmann J, Schankin C, Akerman S. Pathophysiology of migraine: a disorder of sensory processing. Physiol Rev. 2017;97(2):553-622. https:// doi.org/10.1152/physrev.00034.2015. 
43. Blake P, Burstein R. Emerging evidence of occipital nerve compression in unremitting head and neck pain. J Headache Pain. 2019;20(1):76. https://doi.org/10.1186/s10194-019-1023-y.

44. Jose S, Cyriac MC, Dhandapani M. Health problems and skin damages caused by personal protective equipment: experience of frontline nurses caring for critical COVID-19 patients in intensive care units. Indian J Crit Care Med. 2021;25(2):134-9. https://doi. org/10.5005/jp-journals-10071-23713.

45. Jiang Q, Song S, Zhou J, Liu Y, Chen A, Bai Y, et al. The prevalence, characteristics, and prevention status of skin injury caused by personal protective equipment among medical staff in fighting COVID-19: a multicenter, cross-sectional study. Adv Wound Care (New Rochelle). 2020;9(7):357-64. https://doi.org/10.1089/ wound.2020.1212.

46. Madan M, et al. Personal protective equipment and particulate filter use during the COVID-19 pandemic: "acidotic times". Arch Bronconeumol. 2021;57 Suppl 1:83. https://doi.org/10.1016/j. arbres.2020.08.015.

47. Roberge RJ, et al. Surgical mask placement over N95 filtering facepiece respirators: physiological effects on healthcare workers. Respirology. 2010;15(3):516-21. https://doi.org/10.1111/j.14401843.2010.01713.x.

48. Roberge RJ, Coca A, Williams WJ, Powell JB, Palmiero AJ. Physiological impact of the N95 filtering facepiece respirator on healthcare workers. Respir Care. 2010;55(5):569-77.

49. Mardimae A, et al. Modified N95 mask delivers high inspired oxygen concentrations while effectively filtering aerosolized microparticles. Ann Emerg Med. 2006;48(4):391-9, 399 e1-2. https://doi.org/10.1016/j.annemergmed.2006.06.039.

50. Beder A, Büyükkoçak Ü, Sabuncuoğlu H, Keskil ZA, Keskil S. Preliminary report on surgical mask induced deoxygenation during major surgery. Neurocirugia (Astur). 2008;19(2):121-6. https:// doi.org/10.1016/s1130-1473(08)70235-5.

51. Scheid JL, et al. Commentary: physiological and psychological impact of face mask usage during the COVID-19 pandemic. Int $\mathrm{J}$ Environ Res Public Health. 2020;17(18). https://doi.org/10.3390/ ijerph17186655.

52. Smith CL, Whitelaw JL, Davies B. Carbon dioxide rebreathing in respiratory protective devices: influence of speech and work rate in full-face masks. Ergonomics. 2013;56(5):781-90. https://doi.org/ 10.1080/00140139.2013.777128.

53. Alexandrov AV., Alexandrov AW., Practical models of cerebral hemodynamics and waveform recognition, in cerebrovascular ultrasound in stroke prevention and treatment, A. Alexandrow, Editor. 2011, WIley-Blackwell: Oxford. p. 68-213.

54. Lavi S, Gaitini D, Milloul V, Jacob G. Impaired cerebral CO2 vasoreactivity: association with endothelial dysfunction. Am J Physiol Heart Circ Physiol. 2006;291(4):H1856-61. https://doi. org/10.1152/ajpheart.00014.2006.

55. Rhee MSM, Lindquist CD, Silvestrini MT, Chan AC, Ong JJY, Sharma VK. Carbon dioxide increases with face masks but remains below short-term NIOSH limits. BMC Infectious Dis. 2021;21:354. https://doi.org/10.1186/s12879-021-06056-0.

56. Martin-Rodriguez F, et al. Blood biomarkers for assessing headaches in healthcare workers after wearing biological personal protective equipment in a COVID-19 field hospital. J Pers Med. 2021;11(1). https://doi.org/10.3390/jpm11010027.

57. Pellegrino ABW, Davis-Martin RE, Houle TT, Turner DP, Smitherman TA. Perceived triggers of primary headache disorders: a meta-analysis. Cephalalgia. 2018;38(6):1188-98. https://doi.org/10.1177/0333102417727535.

58. Marmura MJ. Triggers, protectors, and predictors in episodic migraine. Curr Pain Headache Rep. 2018;22(12):81. https://doi. org/10.1007/s11916-018-0734-0.

59. Tan BYQ, Chew NWS, Lee GKH, Jing M, Goh Y, Yeo LLL, et al. Psychological impact of the COVID-19 pandemic on health care workers in Singapore. Ann Intern Med. 2020;173(4):317-20. https://doi.org/10.7326/M20-1083.

60. Chew NWS, Lee GKH, Tan BYQ, Jing M, Goh Y, Ngiam NJH, et al. A multinational, multicentre study on the psychological outcomes and associated physical symptoms amongst healthcare workers during COVID-19 outbreak. Brain Behav Immun. 2020;88:559-65. https://doi.org/10.1016/j.bbi.2020.04.049.

61. Zhou NYYL, Dong LY, Li Y, An XJ, Yang J, et al. Prevention and treatment of skin damage caused by personal protective equipment: experience of the first-line clinicians treating 2019-nCoV infection. Int J Dermatol Venereol. 2020;3(2):70-5. https://doi.org/10.1097/ JD9.0000000000000085.

62. Rasmussen BK, Olesen J. Symptomatic and nonsymptomatic headaches in a general population. Neurology. 1992;42(6):1225-31. https://doi.org/10.1212/wnl.42.6.1225.

63. Li Y, Tokura H, Guo YP, Wong ASW, Wong T, Chung J, et al. Effects of wearing N95 and surgical facemasks on heart rate, thermal stress and subjective sensations. Int Arch Occup Environ Health. 2005;78(6):501-9. https://doi.org/10.1007/s00420-0040584-4.

64. Locatelli SM, LaVela SL, Gosch M. Health care workers' reported discomfort while wearing filtering face-piece respirators. Workplace Health Saf. 2014;62(9):362-8. https://doi.org/10.3928/ 21650799-20140804-03.

65. Scarano A, Inchingolo F, Lorusso F. Facial skin temperature and discomfort when wearing protective face masks: thermal infrared imaging evaluation and hands moving the mask. Int J Environ Res Public Health. 2020;17(13). https://doi.org/10.3390/ ijerph17134624.

66. Sprecher AG, Caluwaerts A, Draper M, Feldmann H, Frey CP, Funk $\mathrm{RH}$, et al. Personal protective equipment for filovirus epidemics: a call for better evidence. J Infect Dis. 2015;212(Suppl 2):S98-S100. https://doi.org/10.1093/infdis/jiv153.

67. Honda H, Iwata K. Personal protective equipment and improving compliance among healthcare workers in high-risk settings. Curr Opin Infect Dis. 2016;29(4):400-6. https://doi.org/10.1097/QCO. 0000000000000280.

68. Baig AS, Knapp C, Eagan AE, Radonovich LJ Jr. Health care workers' views about respirator use and features that should be included in the next generation of respirators. Am J Infect Control. 2010;38(1):18-25. https://doi.org/10.1016/j.ajic.2009.09. 005.

69.• Chua MH, et al. Face masks in the new COVID-19 normal: materials, testing, and perspectives. Research (Wash D C). 2020;2020: 7286735. https://doi.org/10.34133/2020/7286735. A comprehensive review discussing the technical details of respirator and face mask design, highlighting the recent engineering advances made in research and development for future applications.

Publisher's Note Springer Nature remains neutral with regard to jurisdictional claims in published maps and institutional affiliations. 